QUARTERLY TECHNICAL PROGRESS REPORT 1

OCTOBER - DECEMBER, 1992

\title{
DEVELOPMENT OF VANADIUM-PHOSPHATE CATALYSTS FOR METHANOL PRODUCTION BY SELECTION OXIDATION OF METHANE
}

\section{Prepared for}

Gary Stiegel (Technical Project Officer)

U. S. Department of Energy

Pittsburgh Energy Technology Center

Pittsburgh, Pennsylvania 15236

By

Robert L. McCormick (Principal Investigator)

Mahesh C. Jha (Program Manager)

AMAX Research \& Development Center

Golden, Colorado 80403-7499

DOE Contract No. DE-AC22-92PC92110

Contract Date: October 1, 1992

Anticipated Completion Date: March 31, 1995

Government Award for Current Fiscal Year: $\$ 175,400$

March 4, 1993 


\title{
LEGAL NOTICE
}

\section{THIS REPORT WAS PREPARED BY AMAX RESEARCH \& DEVELOPMENT CENTER AS AN ACCOUNT OF WORK SPONSORED BY THE PITTSBURGH ENERGY TECHNOLOGY CENTER. NEITHER AMAX RESEARCH \& DEVELOPMENT CENTER NOR ANY PERSON ACTING ON ITS BEHALF:}

\author{
(A) MAKES ANY WARRANTY, EXPRESSED OR IMPLIED, \\ WITH RESPECT TO THE USE OF ANY INFORMATION, \\ APPARATUS, METHOD, OR PROCESS DISCLOSED IN \\ THIS REPORT OR THAT SUCH USE MAY NOT \\ INFRINGE PRIVATELY OWNED RIGHTS; OR \\ (B) ASSUMES ANY LIABILITIES WITH RESPECT TO THE \\ USE OF, OR FOR THE DAMAGES RESULTING FROM \\ THE USE OF, ANY INFORMATION, APPARATUS, \\ METHOD, OR PROCESS DISCLOSED IN THIS \\ REPORT.
}

\section{DISCLAIMER}

This report was prepared as an account of work sponsored by an agency of the United States Government. Neither the United States Government nor any agency thereof, nor any of their employees, makes any warranty, express or implied, or assumes any legal liability or responsibility for the accuracy, completeness, or usefulness of any information, apparatus, product, or process disclosed, or represents that its use would not infringe privately owned rights. Reference herein to any specific commercial product, process, or service by trade name, trademark, manufacturer, or otherwise does not necessarily constitute or imply its endorsement, recommendation, or favoring by the United States Government or any agency thereof. The views and opinions of authors expressed herein do not necessarily state or reflect those of the United States Government or any agency thereof. 


\section{TABLE OF CONTENTS}

Page

EXECUTIVE SUMMARY $\ldots \ldots \ldots \ldots \ldots \ldots \ldots \ldots$

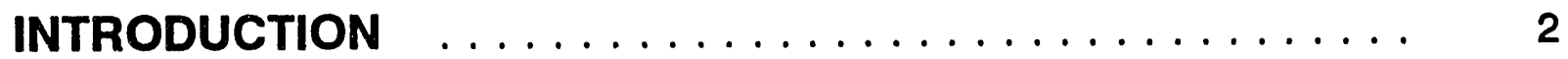

PROJECT DESCRIPTION $\ldots \ldots \ldots \ldots \ldots \ldots \ldots \ldots \ldots \ldots$

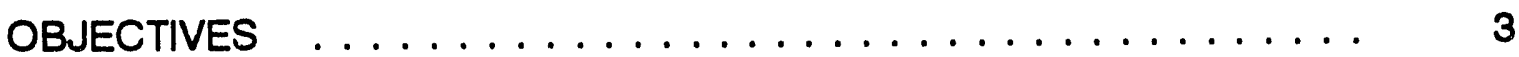

PROJECT OVERVIEW $\ldots \ldots \ldots \ldots \ldots \ldots \ldots \ldots \ldots \ldots \ldots$

PROJECT STATUS $\ldots \ldots \ldots \ldots \ldots \ldots \ldots \ldots \ldots$

CATALYST SYNTHESIS AND CHARACTERIZATION $\ldots \ldots \ldots \ldots \ldots$ Apparatus and Methods $\ldots \ldots \ldots \ldots \ldots \ldots \ldots \ldots$ Results ........................ 6

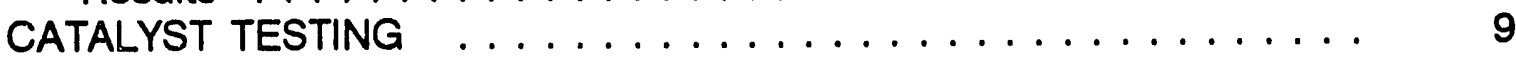

Apparatus and Methods $\ldots \ldots \ldots \ldots \ldots \ldots \ldots$

Results . . . . . . . . . . . . . . . . . . . . . 10

PLANNED ACTIVITIES $\ldots \ldots \ldots \ldots \ldots \ldots \ldots \ldots$

CATALYST SYNTHESIS AND CHARACTERIZATION $\ldots \ldots \ldots \ldots \ldots 12$

CATALYST TESTING $\ldots \ldots \ldots \ldots \ldots \ldots \ldots \ldots \ldots \ldots \ldots$

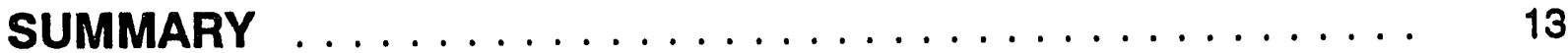

REFERENCES $\ldots \ldots \ldots \ldots \ldots \ldots \ldots \ldots \ldots \ldots \ldots$

APPENDIX A. MASS FLOW CONTROLLER AND PUMP

CALIBRATIONS

APPENDIX B. SAMPLE GAS CHROMATOGRAPH OUTPUT 


\section{LIST OF TABLES}

Page

Table 1. BET Surface Areas for Precursor Samples . . . . . . . . . 7

Table 2. Results of Blank Reactor Tests $\ldots \ldots \ldots \ldots \ldots \ldots$

\section{LIST OF FIGURES}

Figure 1. X-ray powder diffraction patterns of catalyst precursors.

Figure 2. X-ray powder diffraction patterns of catalyst activated for 24 hours at $500^{\circ} \mathrm{C}$ with direct

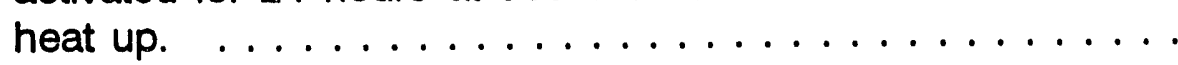

Figure 3. Block flow diagram of bench-scale reactor system. 


\section{EXECUTIVE SUMMARY}

Under the project entitled "Development of Vanadium-Phosphate Catalysts for Methanol Production by Selective Oxidation of Methane", Contract No. DE-AC2292PC92110, Amax R\&D will perform laboratory scale development of a promising, practical catalyst for the selective oxidation of methane to methanol. The primary component of this catalyst is vanadium-phosphate (NPO) which has shown good activity and selectivity in the partial oxidation of $n$-butane and propane but has not been studied in detail for methane oxidation.

The goal of the project is to develop a catalyst which allows methane oxidation to methanol to be conducted at high conversion and selectivity. A low $\mathrm{CH}_{4} / \mathrm{O}_{2}$ ratio will be employed with air as the source of oxygen. Temperatures belows $600^{\circ} \mathrm{C}$ and pressures up to $20 \mathrm{~atm}$ are to be investigated. The use of steam in the feed gas will also be investigated. The catalyst development strategy will be to utilize promoters and supports to improve the activity and selectivity of the unmodified VPO catalyst.

This document is the first quarterly technical progress report for this project. During the first quarter, we have completed Task 1, Laboratory Setup, and this report describes activities and results for this task. Task 1 involved setup of equipment for catalyst synthesis and catalyst testing, including product gas analysis. All of these systems are now fully operational.

Several catalyst preparations were performed using the catalyst synthesis system and X-ray diffraction patterns of the dried catalyst precursors conformed closely to those reported in the literature for active and selective butane oxidation catalysts. These catalyst precursors were activated in a methane/air environment at $500^{\circ} \mathrm{C}$ yielding samples with the characteristic X-ray diffraction pattern of vanadyl pyrophosphate, which is thought to be the active phase in butane oxidation.

The catalyst testing reactor system was used to perform blank (empty) reactor runs over a wide range of temperatures, pressure, and flow rates. No methane conversion was observed at temperatures of $500^{\circ} \mathrm{C}$ or lower in any of the tests. At higher temperatures, significant methane conversion to carbon dioxide was observed. At $550^{\circ} \mathrm{C}, 300 \mathrm{psig}$, and the highest flow rate studied, reactor ignition was observed. Based on the results of these blank runs, we conclude that catalyst testing should be performed at temperatures not to exceed $500^{\circ} \mathrm{C}$. 


\section{INTRODUCTION}

This document is the first quarterly technical progress report under Contract No. DE-AC22-92PC92110, "Development of Vanadium-Phosphate Catalysts for Methanol Production by Selective Oxidation of Methane". During the first quarter, we have completed Task 1, Laboratory Setup, and this report describes activities and results for this task. Task 1 involved setup of equipment for catalyst synthesis and catalyst testing, including product gas analysis. All of these systems are now fully operational, as discussed below. Also presented are preliminary vanadiumphosphate catalyst synthesis results and the results of blank reactor runs in the catalyst testing system. 


\section{PROJECT DESCRIPTION}

\section{OBJECTIVES}

The specific objectives of this project are to:

- Develop an economical catalyst for partial oxidation of methane to methanol.

- Determine optimum conditions for methanol production from methane using VPO catalysts.

- Utilize promoters and catalyst supports to improve methanol yield relative to the base case catalysts.

- Provide a preliminary understanding of how these promoters and supports actually affect catalyst properties.

- Use the information obtained to prepare advanced catalysts which will be tested for activity, selectivity, and stability.

- Develop a simplified methanol production process flowsheet based on these advanced catalysts.

\section{PROJECT OVERVIEW}

Under the project entitled "Development of Vanadium-Phosphate Catalysts for Methanol Production by Selective Oxidation of Methane", Amax R\&D will perform laboratory scale development of a promising, practical catalyst for the selective oxidation of methane to methanol. The primary component of this catalyst is vanadium-phosphate (VPO) which has shown good activity and selectivity in the partial oxidation of $n$-butane and propane but has not been studied in detail for methane oxidation.

The goal of the project is to develop a catalyst which allows methane oxidation to methanol to be conducted at high conversion and selectivity. A low $\mathrm{CH}_{4} / \mathrm{O}_{2}$ ratio will be employed with air as the source of oxygen. Temperatures below $600^{\circ} \mathrm{C}$ and pressures up to $20 \mathrm{~atm}$ are to be investigated. The use of steam in the feed gas will also be investigated. The catalyst development strategy will be to utilize promoters and supports to improve the activity and selectivity of the unmodified VPO catalyst. Catalysts will be characterized by nitrogen adsorption/ desorption, elemental analysis, X-ray powder diffraction, and FTIR.

The project is divided into four tasks: 
- Task 1. Laboratory Setup

Equipment for catalyst preparation and reactivity testing will be set up and tested. Gas analytical procedures will be developed. Blank reactor runs will be conducted.

- Task 2. Process and Catalyst Variable Study

Tests will be conducted to determine the optimum conditions of temperature, pressure, $\mathrm{CH}_{4} / \mathrm{O}_{2}$ ratio, $\mathrm{H}_{2} \mathrm{O} / \mathrm{CH}_{4}$ ratio, space velocity, and catalyst $\mathrm{P}: \mathrm{V}$ ratio for high activity and selectivity in methanol production.

- Task 3. The Effect of Promoters and Supports

Several promoters and supports will be tested. The measured response will be activity and selectivity in the methane oxidation reaction to methanol. Catalyst characterization will provide a fundamental understanding of these effects.

\section{- Task 4. Advanced Catalyst Testing}

Advanced catalysts which are both promoted and supported will be prepared. These catalysts will be tested in runs of relatively long duration (200 hours) to determine long-term activity, selectivity, and stability in methane oxidation to methanol. 


\section{PROJECT STATUS}

The objectives of Task 1 were to set up and test equipment for catalyst synthesis and testing. This included a glass apparatus for catalyst synthesis, a controlled atmosphere furnace for catalyst drying, calcining, and activation, a small reactor system for catalyst activity/selectivity testing, and a gas chromatograph for analysis of reactor product gases. As of the end of the last quarter of 1992, all of these systems were operational and the objectives of Task 1 were achieved. The following paragraphs describe the equipment setup under Task 1, as well as the experimental methods employed wheri using this equipment. In addition, the results of preliminary catalyst synthesis experiments and blank (empty) reactor runs are reported.

\section{CATALYST SYNTHESIS AND CHARACTERIZATION}

\section{Apparatus and Methods}

Catalyst synthesis is conducted in a $500 \mathrm{ml}$ glass, round bottom, threenecked flask. The flask is equipped with a reflux condenser on neck one and a teflon impeller-shaft assembly on neck two. The third neck is used for reagent addition. The flask can be heated with an electric resistance heating mantle.

Typical procedures for synthesis of VPC butane oxidation catalysts have been reviewed in considerable detail by Hodnett (1985) and Hutchings (1991). Procedures can generally be divided into the categories of aqueous and nonaqueous preparations. Additionally, procedures for activating the catalyst such as washing in boiling water and calcining in hydrocarbon/air mixtures are also discussed. There is no general consensus in the literature on optimum procedures, so we have undertaken a preliminary catalyst synthesis study utilizing both aqueous and non-aqueous preparation. Preparations were evaluated by measurement of X-ray powder diffraction patterns (Philips X'PERT System) and BET surface areas (Quantachrome Quantasorb-1).

The following samples were prepared using the procedures of Busca and coworkers (1986):

- 1504-61A

Fifteen grams of $\mathrm{V}_{2} \mathrm{O}_{5}$ was dissolved in 37 percent aqueous $\mathrm{HCl}$. The solution was stirred and refluxed for 3 hours. Twenty-two and 8 tenths grams of phosphoric acid was then added, yielding a P:V ratio of 1.2. Refluxing was continued for another 2 hours. The solution was poured into a beaker and water was evaporated overnight at $150^{\circ} \mathrm{C}$, yielding a light blue solid. 
A fraction of the sample produced in 1504-61A was washed in boiling water for 1 hour and then air dried at $150^{\circ} \mathrm{C}$ for 24 hours.

- $1504-64$

Fifteen grams of $\mathrm{V}_{2} \mathrm{O}_{5}$ was suspended in $90 \mathrm{ml}$ of isobutyl alcohol and $60 \mathrm{ml}$ of benzyl alcohol. The suspension was stirred and refluxed for 3 hours and then cooled overnight with stirring before the addition of 16.16 grams of 99 percent ortho- $\mathrm{H}_{3} \mathrm{PO}_{4}$. This yielded a P:V ratio of 1 . After the phosphorous addition, the solution was heated and refluxed for 2 hours. The resulting slurry was filtered, washed, and dried.

- $1504-66$

A procedure identical to that for 1504-64 was followed except that 19.58 grams of 99 percent ortho- $\mathrm{H}_{3} \mathrm{PO}_{4}$ was added, yielding a $\mathrm{P}: \mathrm{V}$ ratio of 1.2 .

There is much experimental evidence that activation of the precursor to form the active catalyst is a critical step in catalyst preparation (Hodnett, 1985; Buchanan et al., 1985; Arnold and Sundaresan, 1988). This activation is typically carried out in the reaction gas environment (1 percent butane in air for maleic anhydride catalysts) and may take as long as 48 hours. The heating rate can affect the activation results. Steam has been shown to accelerate activation (Arnold and Sundaresan, 1988). Suitable activation conditions for methane oxidation catalysts have not yet been determined. We have elected to activate using 3 percent methane in air for these preliminary tests. Activation was performed by heating directly to $500^{\circ} \mathrm{C}$ and holding for 24 hours under the methane/air mixture.

\section{Results}

$X$-ray powder diffraction patterns are shown for each of the dried (precursor) samples in Figure 1. Analysis of the peaks indicates that 1504-61A is roughly 50 percent $\mathrm{VO}\left(\mathrm{HPO}_{4}\right)-0.5 \mathrm{H}_{2} \mathrm{O}$, the desired precursor phase (Hutchings, 1991). The sample also contains a significant amount of $\mathrm{VO}\left(\mathrm{H}_{2} \mathrm{PO}_{4}\right)_{2}$ and other unidentified phases. Washing of this sample in boiling water (1504-61B) effectively removes the peaks of $\mathrm{VO}\left(\mathrm{H}_{2} \mathrm{PO}_{4}\right)_{2}$ and the other unidentified phases, leaving only the desired phase. Peaks in both of these samples are very sharp, indicating a high degree of crystallinity.

Samples prepared from non-aqueous solution yielded similar diffraction patterns which are also shown in Figure 1. Sample 1504-64 (P:V = 1) exhibits the peaks of $\mathrm{VO}\left(\mathrm{HPO}_{4}\right)-0.5 \mathrm{H}_{2} \mathrm{O}$, but they are much broader than those observed for the aqueous preparations. This is also true for 1504-66 ( $P: V=1.2)$, although the peaks are slightly sharper. 


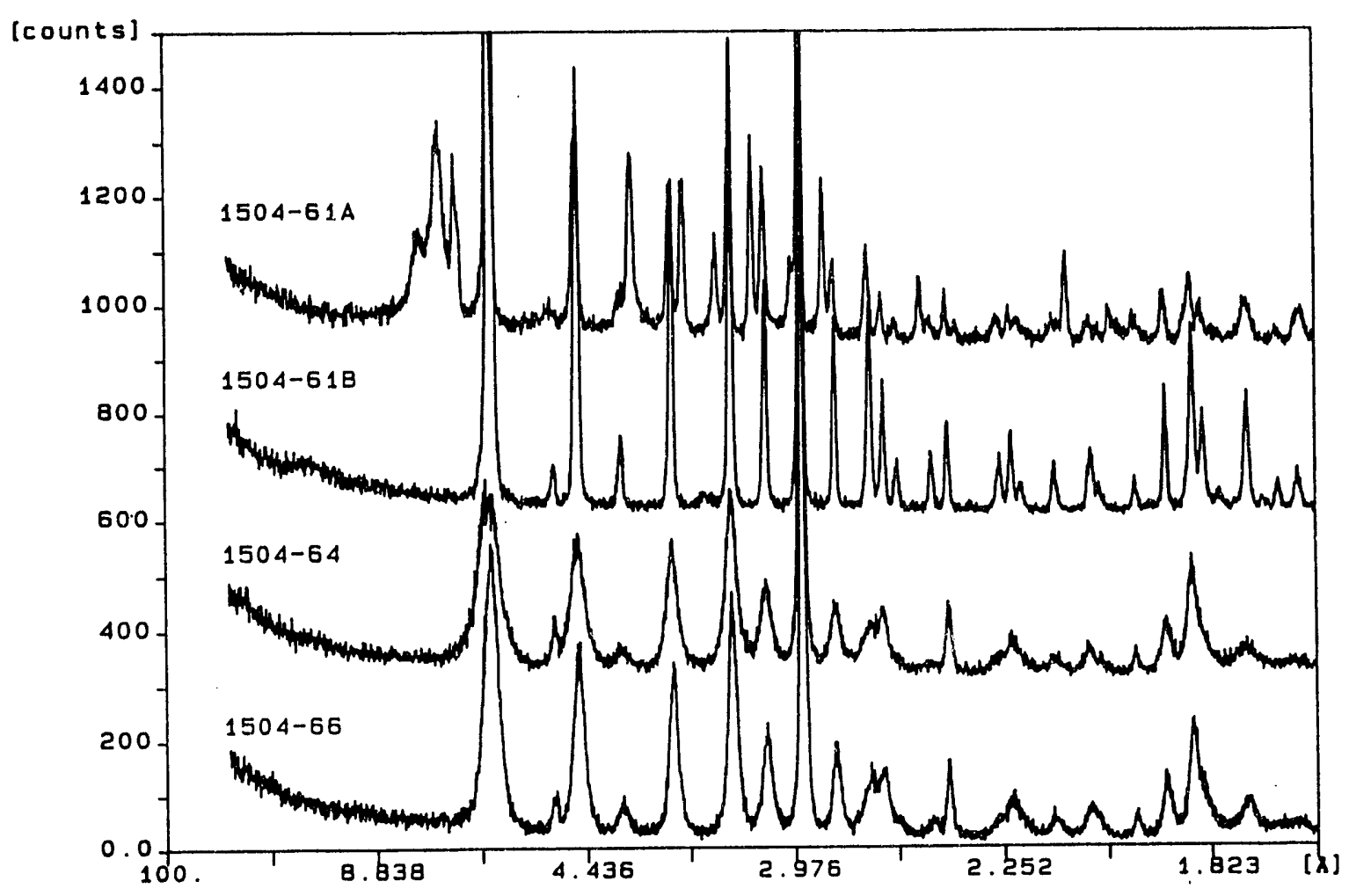

Figure 1. X-ray powder diffraction patterns of catalyst precursors.

Surface areas for the precursor samples were measured by the BET method with nitrogen. These data are reported in Table 1 and agree quite well with literature values. Non-aqueous preparations exhibit much higher surface areas than aqueous preparations. Higher surface area catalysts are known to be active and selective at lower temperatures in butane oxidation (Hutchings, 1991).

Table 1. BET Surface Areas

for Precursor Samples

\begin{tabular}{lc} 
Sample & Surface Area $\left(\mathrm{m}^{2} / \mathrm{g}\right)$ \\
\cline { 2 - 2 } $1504-61 \mathrm{~A}$ & 2.4 \\
$1504-61 \mathrm{~B}$ & 4.0 \\
$1504-64$ & 32.9 \\
$1504-66$ & 35.8
\end{tabular}


$X$-ray diffraction results for activated samples are shown in Figure 2. Both diffraction patterns are characteristic of vanadyl pyrophosphate, which is thought to be the active phase in butane oxidation catalysts (Busca et al., 1986). However, the peak at $d=4.18$ angstroms is displaced by 0.1 angstrom from its expected position. This may indicate that transformation of the precursor to vanadyl pyrophosphate is incomplete. To examine this possibility, the samples will be further activated for a total of 48 hours during the next month.

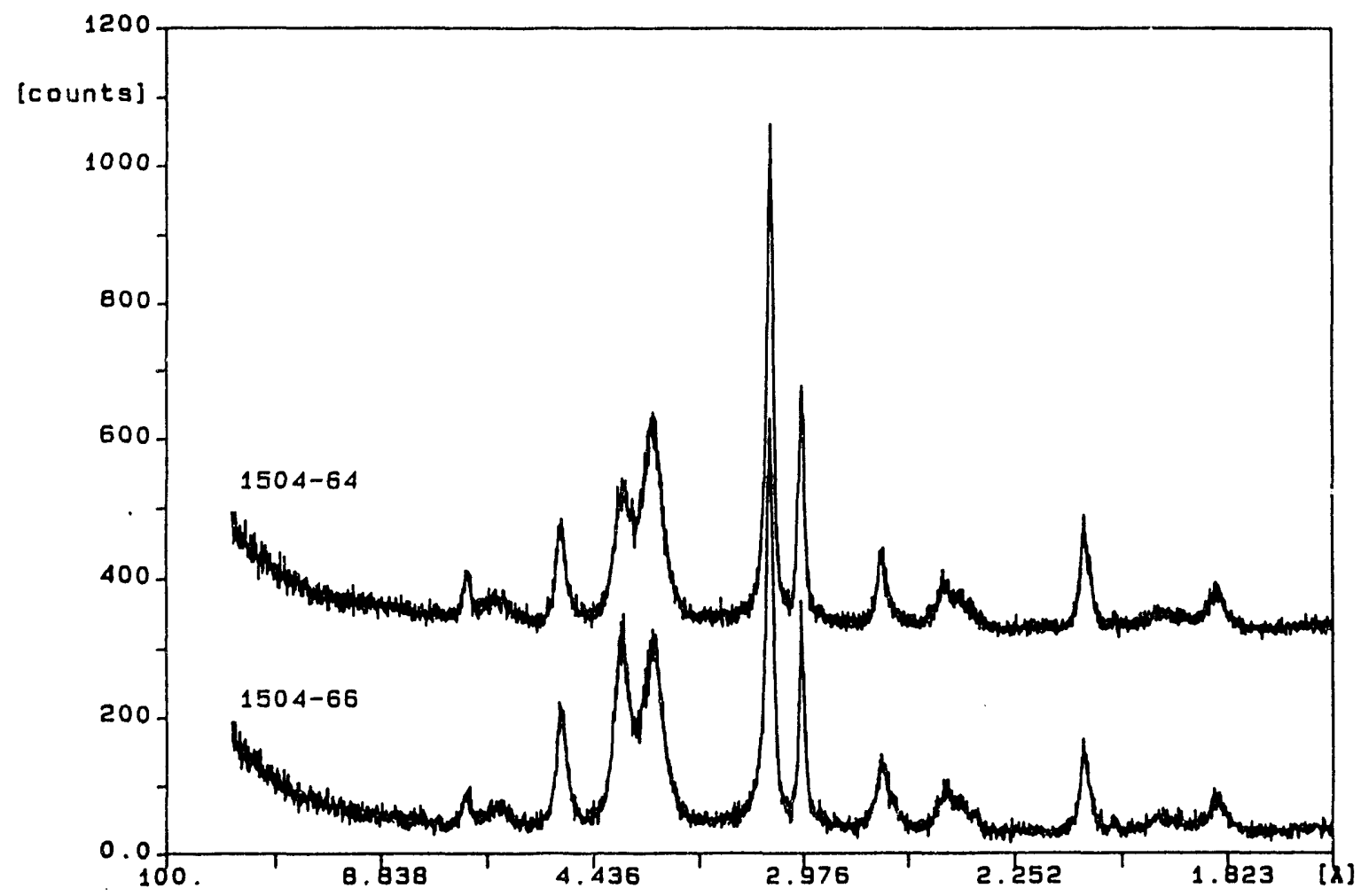

Figure 2. X-ray powder diffraction patterns of catalyst activated for 24 hours at $500^{\circ} \mathrm{C}$ with direct heat up.

These catalyst preparation results show that our catalyst synthesis system and methodology are capable of reproducing catalysts described in the patent and scientific literature. Thus, one major objective of Task 1 has been accomplished. 


\section{Apparatus and Methods}

Catalysts are to be tested in a small fixed-bed reactor system. A flow schematic for this system is shown in Figure 3. The system includes Brooks mass flow controllers for metering gas flow. These mass flow controllers (MFCs) are feed from cylinders of ultra-high purity methane, air, and technical grade nitrogen. The mass flo'w controllers meter these gases into a manifold which is back pressured to 350 psig. The mass flow controllers were calibrated and the calibrations converted to standard temperature $\left(21^{\circ} \mathrm{C}\right)$ and pressure (14.7 psia). These calibrations are shown in Appendix A. Gases from the manifold can be sampled to the GC to obtain a feed gas composition. Gases from the manifold flow to a steam generator which is heated by an electric resistance heating element. Water is supplied to the steam generator from an Eldex metering pump. A calibration curve for this pump is also shown in Appendix A. Steam-containing gas mixtures flow from the steam generator to the reactor inlet through short transfer lines which are wrapped with heating tape and insulated. Gases flow upward through the small fixed-bed reactor. The reactor consists of nominally $0.775-\mathrm{cm}$ diameter stainless steel tube and is $19.05 \mathrm{~cm}$ long. Typically, a catalyst bed of from 1 to $5 \mathrm{~cm}$ in height is used with fore and aft sections packed with inert material. A thermocouple extends along the reactor center line into the catalyst bed. The reactor is heated with an electric furnace controlled by a small PID controller. A thermocouple near the furnace elements is used as input to the controller. Reactor pressure is controlled by a back pressure regulator. Just upstream of this regulator, gases can be bled to the GC for analysis. All post reactor tubing and sample lines are wrapped with heating tape and insulated.

Gas analysis is accomplished with a Hewlett-Packard 5890A gas chromatograph coupled with a 3396A integrator. Helium is used as the carrier gas and purified to remove traces of moisture and oxygen. The GC is equipped with a gas sampling/flow reversal valve and a column isolation valve. Separation of product gases is accomplished by using two columns. A Chromosorb 107 column is used to separate formaldehyde, water, and methanol. A Carbosphere column is used for separation of air (single peak), carbon monoxide, methane, and carbon dioxide. Gases are detected with a thermal conductivity detector. The gas analysis procedure is to inject the sample onto the Chromosorb column which is in series with the Carbosphere column. Air, $\mathrm{CO}, \mathrm{CH}_{4}$, and $\mathrm{CO}_{2}$ pass through the Chromosorb column and onto the Carbosphere column where they are separated and finally detected. After $\mathrm{CO}_{2}$ is detected, the Carbosphere column is isolated and the Chromosorb column is temperature programmed to separate formaldehyde, water, and methanol which remain on this column at the initially low $\left(65^{\circ} \mathrm{C}\right) \mathrm{GC}$ oven temperature. The oven is programmed to $170^{\circ} \mathrm{C}$ at $30^{\circ} \mathrm{C} /$ minute. A sample gas chromatogram obtained using this procedure is shown in Appendix $B$. This chromatogram was obtained utilizing a standard gas of 1 percent each $\mathrm{CO}, \mathrm{CH}_{4}$, 
and $\mathrm{CO}_{2}$ with injection of a liquid mixture of water, formaldehyde and methanol. The integrator was calibrated using these gas and liquid mixtures.

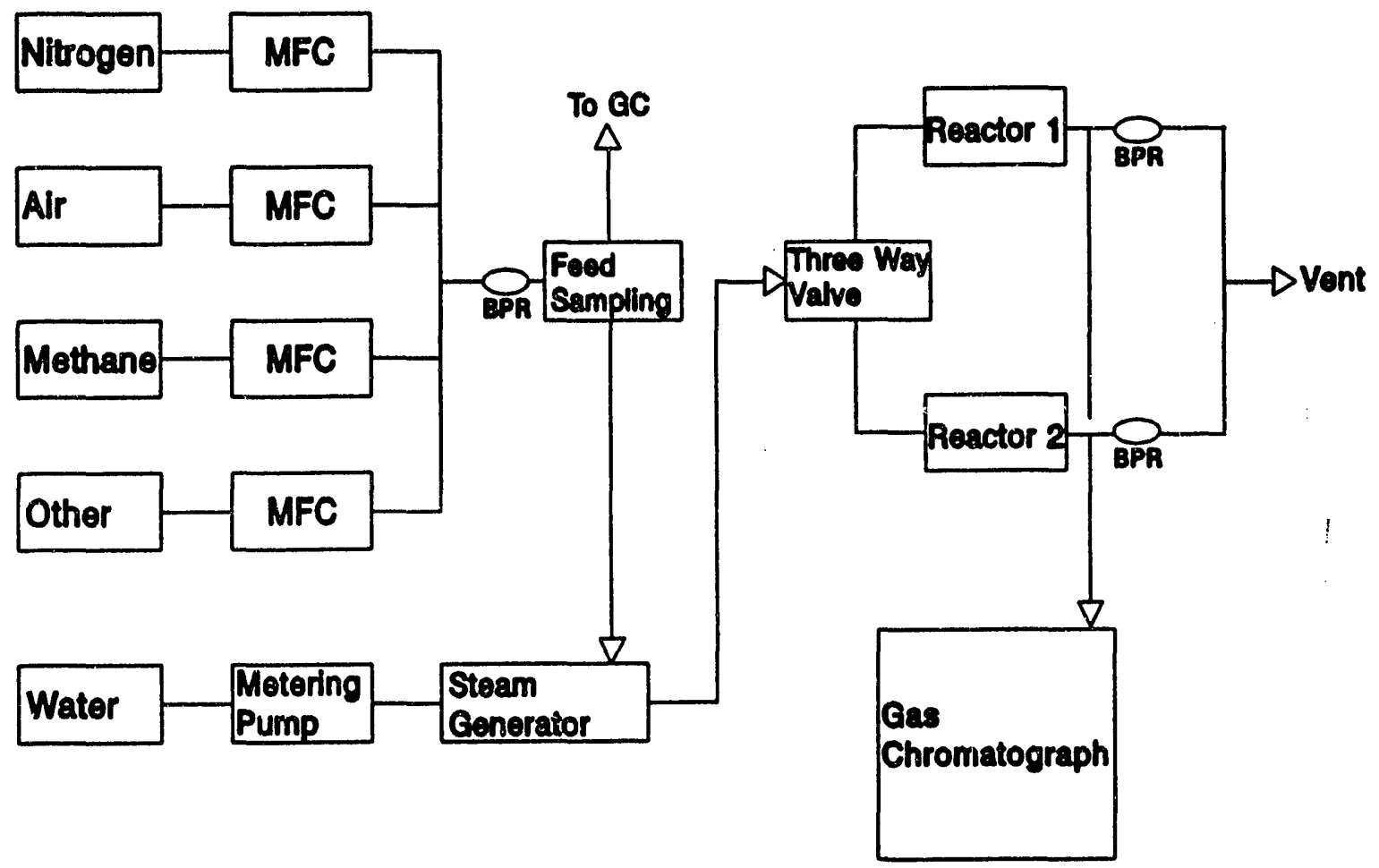

Figure 3. Block flow diagram of bench-scale reactor system.

\section{Results}

Utilizing this reactor system, we have performed a series of blank runs to determine the extent of homogeneous and wall catalyzed methane conversion. The test conditions and results are shown in Table 2. The space time listed in Table 2 is calculated from the reactor volume when empty $\left(8.9802 \mathrm{~cm}^{3}\right)$ and the reactant flow in sccm. Much lower space times (higher space velocities) can be obtained when using a catalyst bed because the bed volume is only a fraction of the total reactor volume. All tests were conducted with a feed of 3 percent methane in air. No selectivities are reported in Table 2 because the only carbon containing product detected was carbon dioxide. 
Table 2. Results of Blank Reactor Tests

\begin{tabular}{|c|c|c|c|c|}
\hline $\begin{array}{c}\text { Temperature, } \\
{ }^{\circ} \mathrm{C}\end{array}$ & $\begin{array}{c}\text { Pressure, } \\
\text { psig }\end{array}$ & $\begin{array}{c}\text { Space Time, } \\
\text { Minutes }\end{array}$ & $\begin{array}{c}\text { Feed, } \\
\% \text { Steam }\end{array}$ & $\begin{array}{c}\text { Conversion, } \\
\% \\
\end{array}$ \\
\hline 300 & 20 & 0.2993 & 0 & 0 \\
\hline 300 & 20 & 0.0299 & 0 & 0 \\
\hline 300 & 300 & 0.2993 & 0 & 0 \\
\hline 300 & 300 & 0.0299 & 0 & 0 \\
\hline 425 & 150 & 0.0599 & 0 & 0 \\
\hline 500 & 300 & 0.0299 & 0 & 0 \\
\hline 525 & 300 & 0.0299 & 0 & 6.5 \\
\hline 550 & 20 & 0.2993 & 0 & 3.2 \\
\hline 550 & 20 & 0.0299 & 0 & 0 \\
\hline 550 & 300 & 0.2993 & 0 & 95.2 \\
\hline 550 & 300 & 0.0299 & 0 & $100.0^{a}$ \\
\hline
\end{tabular}

- Reactor exhibited oscillations typical of ignition/extinction.

These results indicate that the reactor system is operational and that to avoid non-catalytic methane conversion, temperatures below $525^{\circ} \mathrm{C}$ must be utilized, especially at high pressures. At the highest temperature, pressure, and flow rate studied, the reactor exhibited instability typical of reactant ignition and extinction. Based on these results, we will limit the temperature range for catalyst testing to 300 to $500^{\circ} \mathrm{C}$. The start-up of this system indicates achievement of the remaining goals of Task 1. Preliminary testing indicates that the addition of steam to the feed gas reduces conversion at $550^{\circ} \mathrm{C}$ and may, therefore, allow operation at higher temperatures. A detailed set of steam blanks will be conducted as part of the initial process variable study to be performed under Task 2. 


\section{PLANNED ACTIVITIES}

During the second quarter of this project, we plan to initiate activities under Task 2, Process Variable Study. The work to be performed under this task includes an investigation of process variables such as temperature, pressure, space velocity, and feed gas composition on the activity and selectivity of VPO catalysts in methane partial oxidation. Additionally, we will investigate the effect of catalyst preparation variables such as $\mathrm{P}: V$ ratio and activation procedure. Specific activities planned are outlined below.

\section{CATALYST SYNTHESIS AND CHARACTERIZATION}

Activities described above for catalyst synthesis will be expanded so that we can rapidly select a preparation and activation procedure for the initial process variaible study. Catalyst characterization will include $X$-ray diffraction, BET surface area, FTIR, and measurement of $P: V$ ratio. A standard catalyst preparation and activation procedure should be established by the end of January 1993.

\section{CATALYST TESTING}

The catalyst testing reactor will be utilized to perform process variable studies, examining the effect of the variables listed above. These will include a set of blank runs with steam in the feed gas. Based on an initial study employing a wide range of all of the variables, a more narrow range will be selected for examination of catalyst variables such as $\mathrm{P}: \mathrm{V}$ ratio and activation procedure. Initial studies using a wide range of variables should be completed by the end of the second project quarter. Additionally, some information on the effect of $P: V$ ratio and activation procedures should be available. 


\section{SUMMARY}

During this quarter, we completed Task 1, Laboratory Setup. Specifically, a catalyst synthesis apparatus was set up and tested by reproducing VPO catalysts described in the literature. Several catalyst preparations were performed, and the $X$-ray diffraction patterns of the dried catalys: precursors conformed closely to those reported in the literature for active and selective butane oxidation catalysts.

Also, a catalyst testing reactor system with gas chromatographic gas analysis was fabricated and assembled. This system was used to perform blank (empty) reactor runs over a wide range of temperatures, pressure, and flow rates. No metharie conversion was observed at temperatures of $500^{\circ} \mathrm{C}$ or lower in any of the tests. At higher temperatures, significant methane conversion to carbon dioxide was observed. At $550^{\circ} \mathrm{C}, 300 \mathrm{psig}$, and the highest flow rate studied, reactor ignition was observed. Based on the results of these blank runs, we conclude that catalyst testing should be performed at temperatures not to exceed $500^{\circ} \mathrm{C}$. 


\section{REFERENCES}

Arnold, E. W. and Sundaresan, S., "Effect of Water Vapor on the Activity and Selectivity Characteristics of a Vanadium Phosphate Catalyst Towards Butane Oxidation", Appl. Catal. 41225 (1988).

Buchanan, J. S., Apostolakis, J., and Sundaresan, S., "Pretreatment and Activation of a Vanadium Phosphate Catalyst for Butane Oxidation to Maleic Anhydride", Appl. Catal. 1965 (1985).

Busca, G., Cavani, F., Centi, G., and Trifiro, F., "Nature and Mechanism of Formation of Vanadyl Pyrophosphate: Active Phase in n-Butane Selective Oxidation", J. Catal. $\underline{99} 400$ (1986).

Hodnett, B. K., "Vanadium-Phosphorus Oxide Catalysts for the Selective Oxidation of $\mathrm{C}_{4}$ Hydrocarbons to Maleic Anhydride", Catal. Rev. 27373 (1985).

Hutchings, G. J., "Effect of Promoters and Reactant Concentration on the Selective Oxidation of n-Butane to Maleic Anhydride Using Vanadium Phosphorus Oxide Catalysts", Appl. Catal. 721 (1991). 


\section{APPENDIX A}

\section{MASS FLOW CONTROLLER AND PUMP CALIBRATIONS}




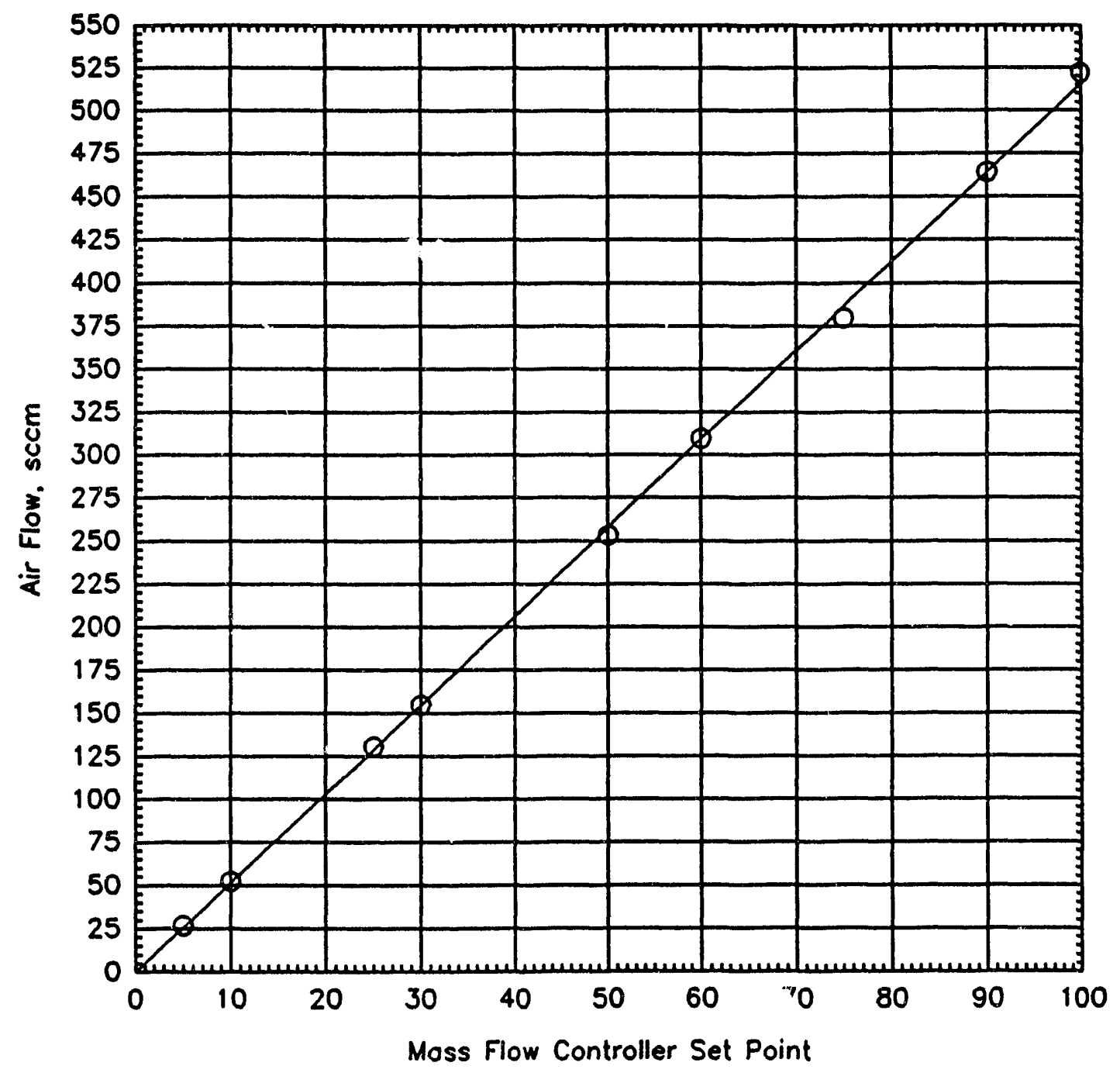

Air mass flow controller calibration. 


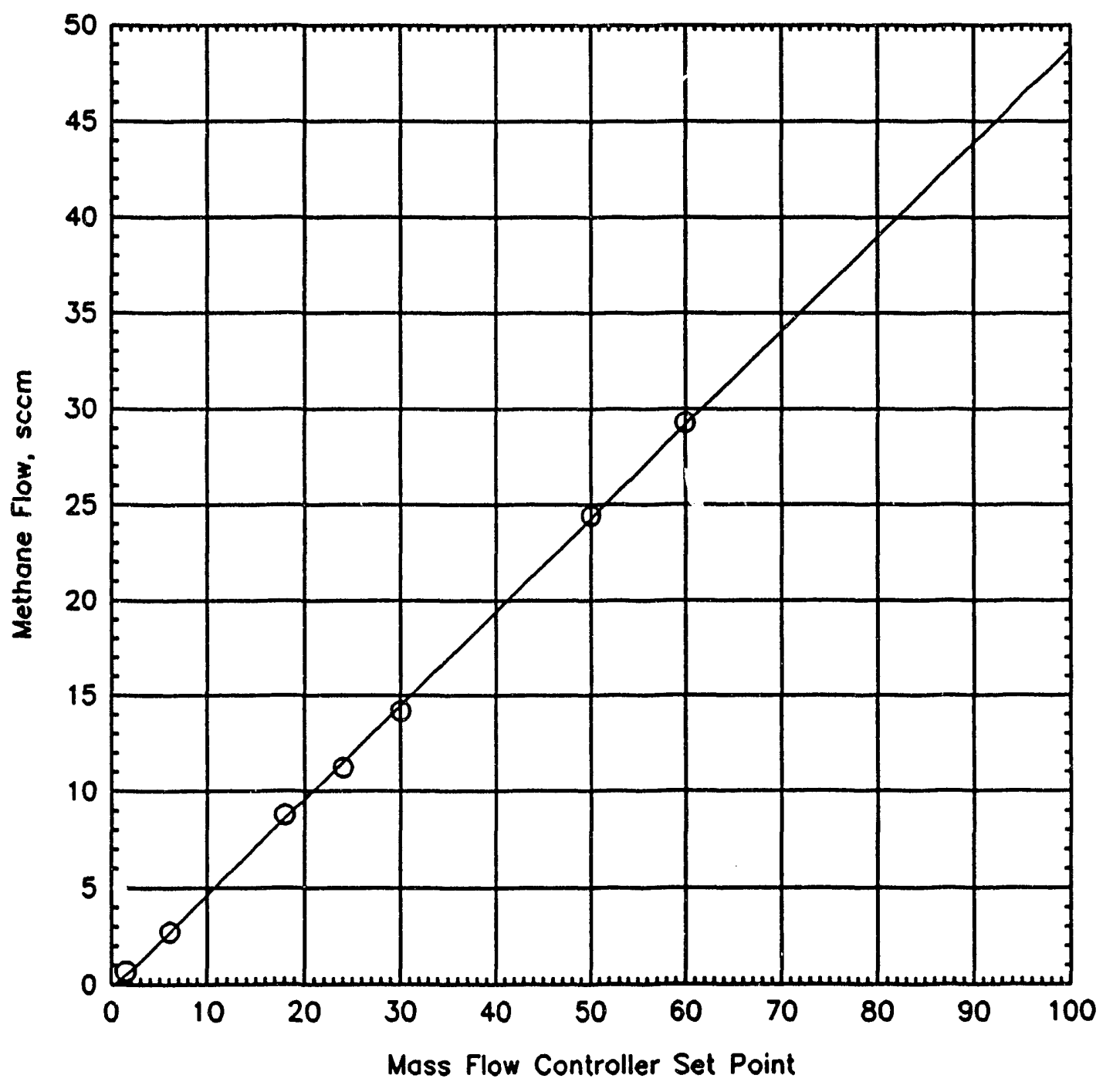

Methane mass flow controller calibration. 


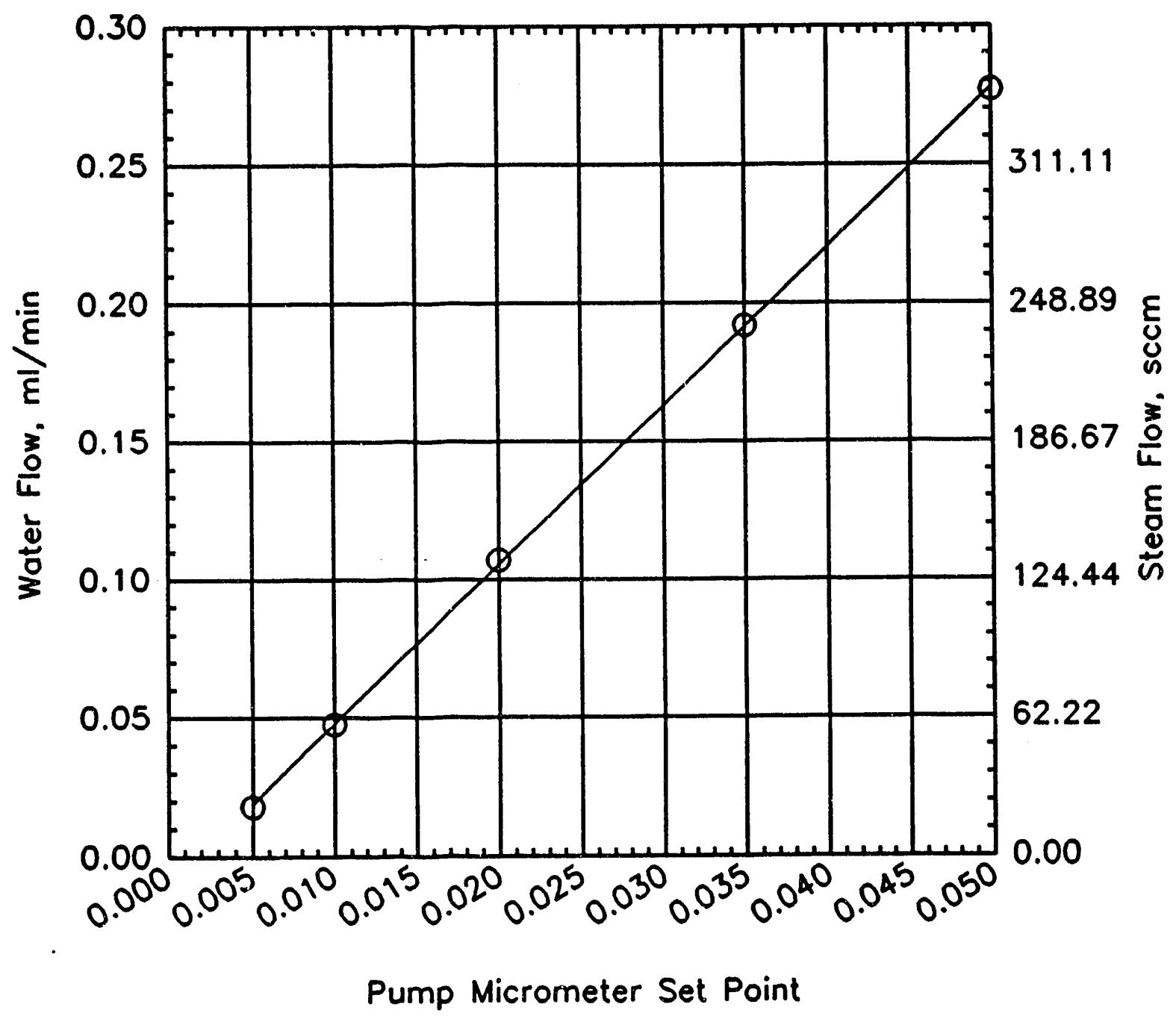

Water pump calibration. 


\section{APPENDIK B}

\section{SAMPLE GAS CHROMATOGRAPH OUTPUT}

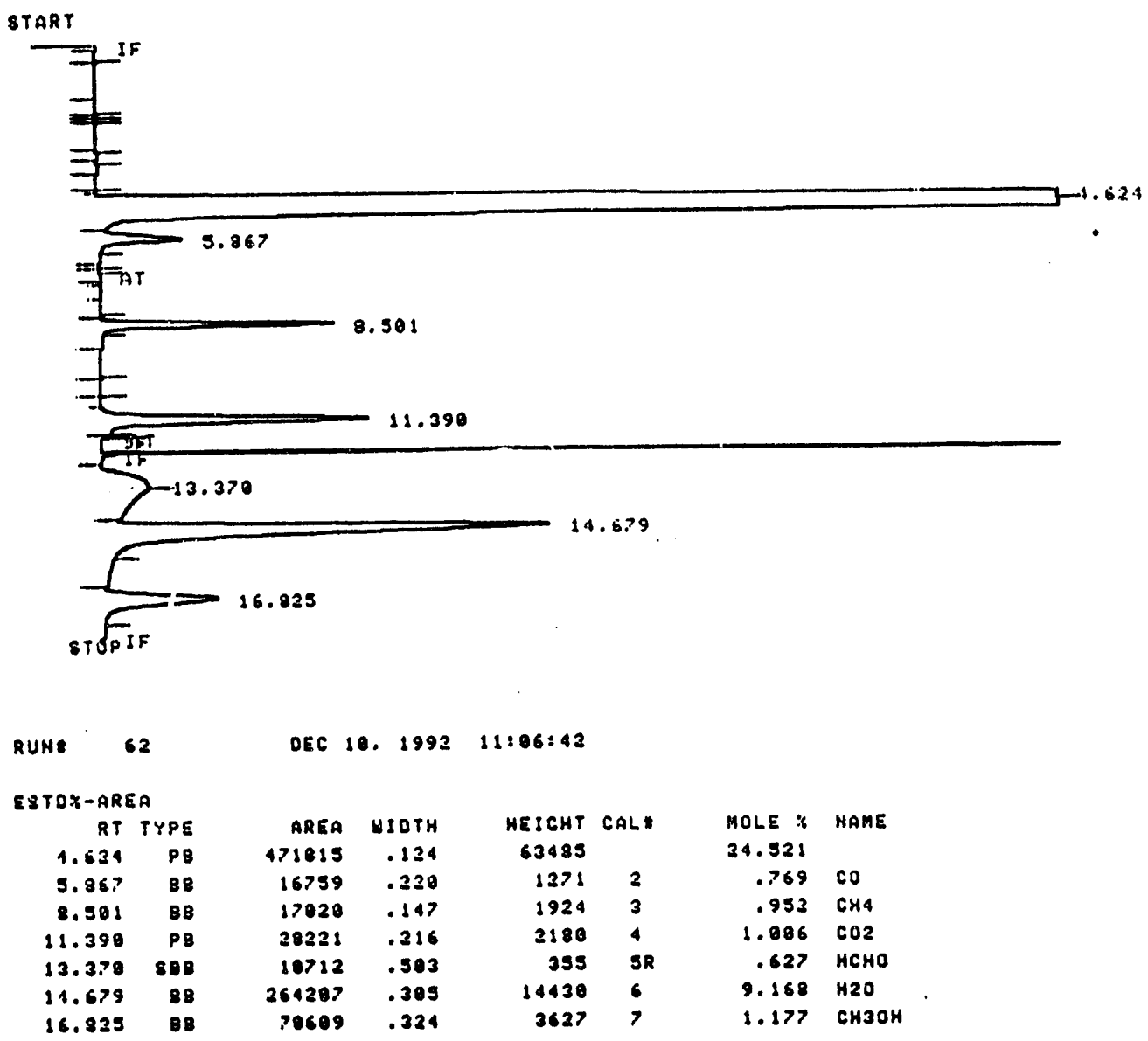



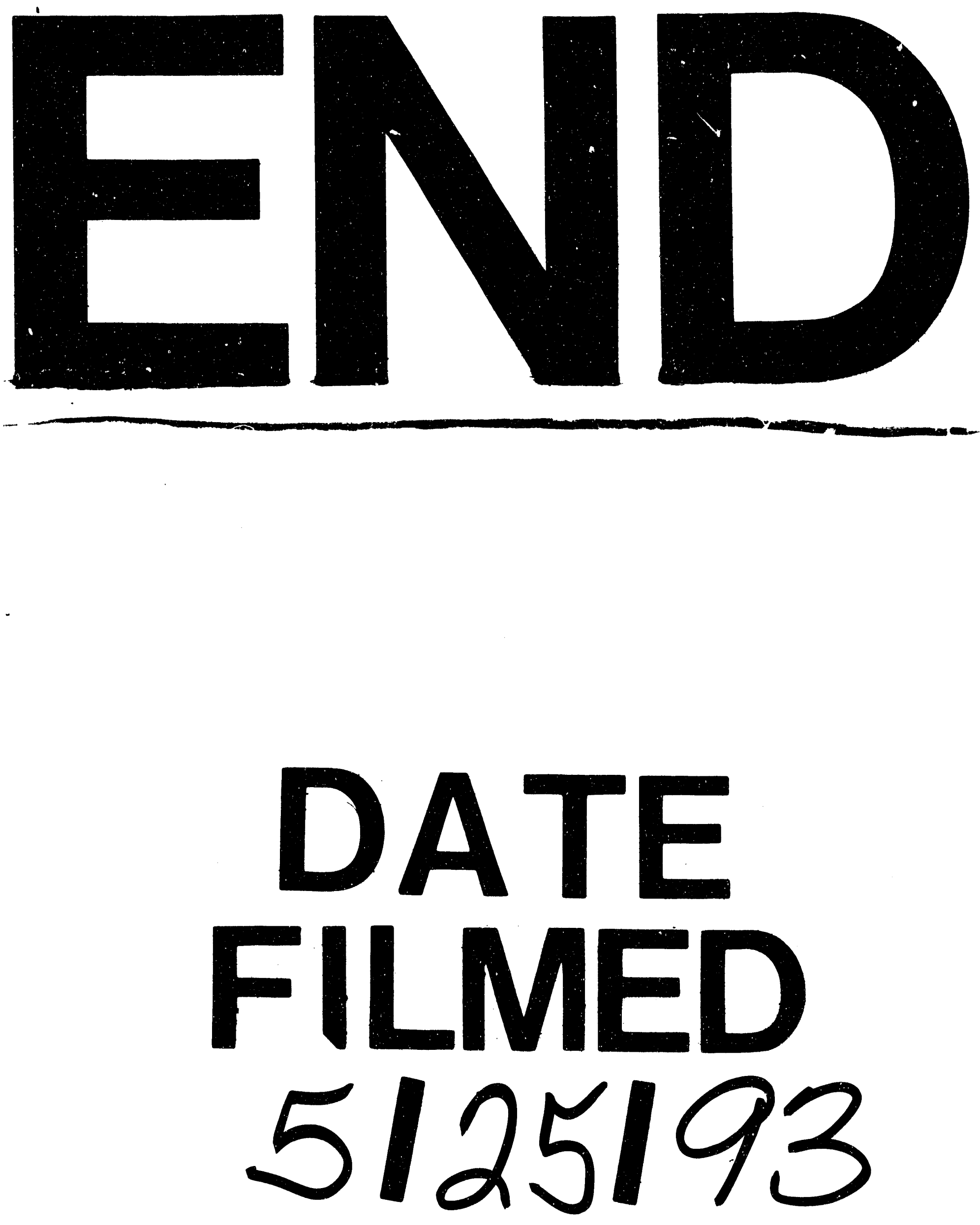
